\title{
Use of performance- and image-enhancing substances among recreational athletes: a quantitative analysis of inquiries submitted to the Danish anti-doping authorities
}

\author{
J. Bojsen-Møller ${ }^{1,2}$, A. V. Christiansen ${ }^{3}$ \\ ${ }^{1}$ Institute of Sports Medicine Copenhagen, Faculty of Health Sciences, Bispebjerg Hospital, University of Copenhagen, Copenhagen, \\ Denmark, ${ }^{2}$ Norwegian School of Sport Sciences, Oslo, Norway, ${ }^{3}$ Department of Sports Science, Faculty of Science, Aarhus \\ University, Aarhus, Denmark \\ Corresponding author: Jens Bojsen-Moller, Institute of Sports Medicine Copenhagen, Faculty of Health Sciences, Bispebjerg \\ Hospital, University of Copenhagen, Bispebjerg Bakke 23, Building 8, $2400 \mathrm{Kbh} . \mathrm{NV}$, Copenhagen, Denmark. E-mail: \\ jens.bojsen.moller@nih.no
}

Accepted for publication 7 August 2009

The use of performance- and image-enhancing drugs/substances (PIED) outside elite sports appears to be increasing, although the current knowledge of the nature of PIED use among recreational athletes is scarce. The present study analyzed enquiries that were submitted to the Danish Anti Doping Agency (ADD) over an 18-month period, to gain knowledge of PIED use among individuals who exercise recreationally in Denmark. One thousand three hundred ninety eight queries were examined with respect to the age and gender of the enquirer, affiliation to sport or exercise and substance in question. The key findings were that the ADD information service is generally used by males in their mid-20s who exercise in gyms and are not engaged in competitive sports. Approximately $15 \%$ of the enquirers were users of anabolic androgenic steroids (AAS) or other substances banned within elite sports by the World Anti Doping Agency, and an additional $15 \%$ considered using such substances. The present results suggest that there is a pronounced interest in the use of AAS and other PIEDs among Danish gym members.
In the past decade, an increasing effort has been made to eliminate the use of doping substances by elite athletes. Anti-doping work has been internationally formalized by the founding of the World Anti Doping Agency (WADA), and some progress toward international harmonization of the doping rules in elite sports has been made (Loland \& Hanstad, 2005). However, many WADA-banned substances, especially anabolic androgenic steroids (AAS), are also used as performance- and imageenhancing drugs/substances (PIEDs) among the recreationally exercising population. Despite the fact, the use of such substances seems to be abundant in the fitness, body-building and gym environments, there is no internationally coordinated effort to counter this use. (Lenehan et al., 1996; Monaghan, 2001; Cafri et al., 2005; Backhouse et al., 2007; Cohen, 2007; Donati, 2007). In 1999, a questionnaire survey in Denmark (Kulturministeriet, 1999) showed that $7.8 \%$ of male Danish gym members had experience with WADA-banned substances, but the study included a rather small population and thus for the general population in Denmark, as well as in most other countries, the prevalence of PIED use is poorly described (Evans-Brown \& McVeigh, 2008).
Excessive use of AAS and certain other PIEDs has been associated with serious adverse health effects (Pope \& Katz, 1998; Bahrke et al., 2000; Monaghan, 2001; Cafri et al., 2005), and therefore an increase in the use of such substances in the general population is of concern per se. The concerns are further emphasized by several factors: (1) strong commercial interests act on the market for drugs and supplements, (2) the knowledge in gym- and strengthtraining environments regarding, e.g. the adverse effects of AAS is at best limited for a large group of users and (3) health services, in contrast within the elite sports milieu, are scarce or non-existent for these individuals (Dawson, 2001; Backhouse et al., 2007; Evans-Brown \& McVeigh, 2009). Taken together, the increasing use of AAS and certain other PIEDs outside the elite sports setting may be potentially introducing serious health issues in a large and presumably growing number of individuals (Pope et al., 2000; Donati, 2007; Gray \& Ginsberg, 2007). To address this issue, knowledge of PIED users and the nature of the substance intake is needed; however, this information is not easily attainable. In Denmark (as well as in a few other countries), the national antidoping agency (ADD) offers individual anonymous 


\section{Bojsen-Møller and Christiansen}

counselling on PIED-related issues, and therefore the purpose of the present study was to analyze enquiries to the ADD in a systematic manner, and to thus gain knowledge on the typical profile of the users of the ADD counselling system, and further, to investigate how AAS and other PIEDs are used within the recreational training and exercise environments.

\section{Methods}

The present study was conducted in collaboration with the ADD, who gave permission to use the data and made it available to the investigators. To protect the identity of those making enquiries, the data were anonymized by the ADD. The study considered all enquiries that were submitted to the ADD by telephone or by an internet-based service over an 18-month period from January 1, 2006 to June 30, 2007 (ADD).

Neither the internet-based system nor the telephone-based system was designed to facilitate post hoc analysis and so users were not required to submit details of their age, gender, affiliation to sport, etc. when submitting an enquiry. In the internet system, the questions were submitted as a written message, containing no additional information other than that provided by the inquirer. This meant the information available varied considerably, as did the structure and content of the questions. Users of the phone-based service were generally encouraged to provide details of age and gender as well as affiliation to sport and any previous experience with PIEDs; however, this was not mandatory. The ADD consultant noted the nature of their question, but the data were not recorded in a systematic manner and therefore, some variation occurred in the available journals.

The internet-based query system was designed so that enquirers could submit questions in seven predefined categories: (1) school assignments; (2) AAS and human growth hormone $(\mathrm{HGH})$; (3) creatine and dietary supplements; (4) therapeutic use exemption (TUE); (5) doping test; (6) EPO and blood-stimulating substances/methods; and (7) statistics and history. It was, however, clear that a large number of questions were posted in an incorrect category. Therefore, all the queries were carefully re-examined by the investigators, and scored within an "information matrix" containing 10 categories: (1) nature of question; (2) age; (3) gender; (4) affiliation; (5 and 6) use of WADA-banned substances; (7) use of other, non-banned substances; (8 and 9) motivation for the query, e.g. "health issues" or "worry of attaining a positivedoping test"; and finally (10) main drug or substance in question (Table 1). The matrix enabled descriptive statistical analysis and a subsequent combination of subgroups within the data material.

Queries that were posted by students wanting information for school projects on doping were discarded because none of them pertained to use or potential use of PIEDs.

The gender of the enquirer was explicitly stated in approximately half of the queries, while in approximately one third of the questions gender could be established by the investigators based on an interpretation of specific statements within the query. The age of the enquirer was registered in most of the telephone-based sessions, but was only available in some of the internet queries. In total, age was known in one fourth of the cases.

\section{Results \\ Total enquiries}

Over the 18-month study period, 1868 queries were submitted to ADD. In total, 1655 came via the internet-based system while 213 were telephone queries. Of these enquiries, 470 were received from students wanting information for their assignments and were thus discarded. The current investigation was therefore based on a total of 1398 enquiries.

\section{Characterization of enquirers \\ Enquirers' background or affiliation}

Most of the enquiries included came from individuals who were training in or otherwise affiliated to gyms $(55 \%)$. Twelve percent of all questions came from individuals who participated in sports, and only a fraction of these $(0.4 \%$ of all questions) were engaged

Table 1. Information matrix

\begin{tabular}{|c|c|c|c|c|c|c|c|c|}
\hline Categories & Scores & & & & & & & \\
\hline $\begin{array}{l}\text { Question } \\
\text { type }\end{array}$ & $\begin{array}{l}\text { General } \\
\text { info }\end{array}$ & $\begin{array}{l}\text { Specific } \\
\text { drug }\end{array}$ & $\begin{array}{l}\text { Adverse } \\
\text { effects }\end{array}$ & $\begin{array}{l}\text { "School } \\
\text { question" }\end{array}$ & $\begin{array}{l}\text { Medical certificate } \\
\text { (TUE) }\end{array}$ & $\begin{array}{l}\text { Exercise/ } \\
\text { training }\end{array}$ & Other & \\
\hline Sex & Male & Female & & & & & & \\
\hline \multicolumn{9}{|l|}{ Age } \\
\hline Affiliation & Sports & Gym & \multicolumn{2}{|c|}{ Relative/peer } & Health personnel & & Other & Unknown \\
\hline Considers doping use & Yes & No & \multicolumn{2}{|c|}{ Unknown/irrelevant } & & & & \\
\hline Uses doping & Yes & No & \multicolumn{2}{|c|}{ Unknown/irrelevant } & & & & \\
\hline Uses other & $\begin{array}{l}\text { Dietary } \\
\text { supplement }\end{array}$ & Medicine & \multicolumn{2}{|c|}{ Unknown/irrelevant } & & & & \\
\hline Worried about health & Yes & No & \multicolumn{2}{|c|}{ Unknown/irrelevant } & & & & \\
\hline $\begin{array}{l}\text { Worried about positive } \\
\text { test }\end{array}$ & Yes & No & \multicolumn{2}{|c|}{ Unknown/irrelevant } & & & & \\
\hline Substance in question & AAS & $\mathrm{HGH}$ & Insulin & EPO/blood & Protein/creatine & $\begin{array}{l}\text { Fatburner/ } \\
\text { ephedrine }\end{array}$ & Other & \\
\hline
\end{tabular}

All enquiries were scored within a matrix based on the 10 categories listed in column 1 . The relevant scores/answers in each category are listed in the respective rows.

TUE, therapeutic use exemption; AAS, anabolic androgenic steroids; $\mathrm{HGH}$, human growth hormone. 
Use of performance- and image-enhancing substances among recreational athletes

in elite sports (not shown in the table). Also, from the nature of the questions posted, it seemed plausible that a large number of individuals whose background could not be directly established $(20 \%)$ were affiliated with gyms. Details regarding the affiliation of those using the system can be seen in Table 2 .

\section{Gender and age}

The age of the enquirer was known in $25 \%$ of the cases $(n=351)$. The mean age was $25 \pm 11$ years (SD) years, with a range of 11-74 years.

The gender of the enquirer was provided in $49 \%$ of the questions $(n=686)$, whereas in $33 \%$ of the cases $(n=461)$, gender was established by the investigators based on an interpretation of specific statements within the query. In $18 \%$ of the queries $(n=251)$, gender could not be ascertained. Out of the 1147 queries in which gender was available, $84 \%$ came from male enquirers and $16 \%$ from females. Although unknown, it seems plausible that this distribution of gender pertains to the entire population of those who have made enquires. Nonetheless, the data on gender distribution in the following sections are based solely on the enquiries in which gender was accessible.

Table 2. Affiliation of the enquirers

\begin{tabular}{lrrrrrr}
\hline Affiliation & \multicolumn{2}{l}{ Number of queries } & & \multicolumn{3}{l}{ Gender distribution } \\
\cline { 2 - 3 } \cline { 5 - 7 } & Absolute & Relative (\%) & & Male & Female & Unknown \\
& 763 & 55 & & 672 & 46 & 45 \\
Gym & 174 & 12 & & 116 & 24 & 34 \\
Sports & 160 & 11 & & 63 & 78 & 19 \\
Relative/peer & 9 & 1 & & & \\
Health personnel & 11 & 1 & & 7 & 2 & 2 \\
Other & 281 & 20 & & 103 & 28 & 150 \\
Unknown & 1398 & $100 \%$ & & 967 & 180 & 251 \\
Total & & & & & & \\
\hline
\end{tabular}

Absolute and relative number of queries and the distribution on gender within each affiliation category.

\section{Affiliation and gender}

Almost all questions (94\%) that were posted by individuals training in gyms were from male enquirers while $6 \%$ were from females. A slightly different distribution was seen for the questions in the sports category ( $83 \%$ males and $17 \%$ females), while the distribution was somewhat oppositely skewed for queries that came from relatives or peers ( $45 \%$ male, $55 \%$ female). It was deemed irrelevant to report the gender distribution in the "health personnel" group (Table 2; see also gender distribution relative to substances in question, in Table 3).

\section{Drugs and substances in question}

In total, 1089 questions (78\%) pertained to a specific drug or substance. The three most common PIEDs were AAS, with $34 \%$ of the questions $(n=374)$, creatine and/or protein, with $22 \%$ of the questions $(n=237)$ and "other dietary supplements," which were enquired about in $16 \%$ of the instances $(n=171)$. The distribution is detailed in Table 3, where cross tabulation to affiliation (gyms or sport) and gender is also shown. From here, it can be seen, for example, that out of the 374 questions concerning AAS, $61 \%(n=227)$ originated from individuals who were training in gyms, while only $1 \%(n=4)$ were from individuals participating in sports. The remaining 143 questions came either from relatives, peers, health personnel or from individuals whose background could not be established. Furthermore, of the 374 questions about AAS, $76 \%(n=284)$ came from male enquirers, while $11 \%(n=40)$ came from females.

\section{Use of AAS and other WADA-banned substances}

In total, $15 \%(n=208)$ of the enquirers (age: $26 \pm 10$ years, range 14-64 years, age data available only on 65 individuals) indicated current or previous use of

Table 3. Drugs in question

\begin{tabular}{|c|c|c|c|c|c|c|}
\hline & Number of queries & Distribution (\%) & Gym sector & Sport & Male & Female \\
\hline AAS & 374 & 34 & 227 & 4 & 284 & 40 \\
\hline Prohormones & 53 & 5 & 41 & 1 & 48 & 3 \\
\hline $\mathrm{HGH}$ & 37 & 3 & 20 & 3 & 26 & 6 \\
\hline Insulin & 5 & 0 & 4 & - & 5 & 0 \\
\hline EPO/blood doping & 35 & 3 & 0 & 1 & 7 & 2 \\
\hline Stimulants & 10 & 1 & 8 & - & 3 & 1 \\
\hline Creatine/protein supplements & 237 & 22 & 194 & 15 & 209 & 11 \\
\hline "fat-burner" supplements & 67 & 6 & 41 & 1 & 30 & 23 \\
\hline Dietary supplements & 171 & 16 & 104 & 17 & 120 & 14 \\
\hline Other & 100 & 9 & 18 & 30 & 42 & 9 \\
\hline Total & 1089 & $100 \%$ & & & & \\
\hline
\end{tabular}

Total absolute and relative distribution of relevant drug/supplement in question, and the distribution with respect to affiliation of the enquirer (gym or sport) and gender.

AAS, anabolic androgenic steroids; HGH, human growth hormone. 


\section{Bojsen-Møller and Christiansen}

WADA-banned substances (upper panel, Table 4), and in $62 \%$ of the cases $(n=129)$, AAS was the drug in question. Of the 208 users of WADA-banned substances, 154 were males and 11 were females, yielding a gender distribution of $93 \%$ males vs $7 \%$ females. One hundred and thirty-one individuals had affiliation to gyms, while seven were affiliated with sports (Table 4).

An additional $15 \%$ of the enquirers $(n=205,179$ males, 18 females) indicated that they were planning or considering the use of WADA-banned substances (158 pertained to AAS). From this group, it could be established that $75 \%(n=154)$ were training in gyms, while only $3 \%(n=7)$ participated in sports. The mean age of those considering the use of doping listed substances was $19 \pm 5$ years, range 14-42 years, with age data available for about half of these individuals $(n=74)$.

Of the 208 users of WADA-banned substances, $58 \%(\mathrm{n}=120)$ expressed health concerns in relation to the drug use, while $<10 \%(n=18)$ reported concerns with respect to obtaining a positive doping test and the concurrent penalty by the anti-doping authorities (note: in Denmark, the anti doping authorities perform doping controls for WADAbanned substances among recreational athletes in commercial gyms; see below). In the group of those considering use of AAS and other WADA-banned substances (205), > 80\% $(n=166)$ were asking questions related to adverse effects and the potential health risks, while $<5 \%(n=7)$ expressed concerns about a positive doping test.

\section{Dietary supplements}

Although $53 \%(n=575)$ of all queries that were related to specific substances pertained to protein/ creatine supplements, herbal extracts or "fatburner" substances, not all enquirers reported an actual use of such substances. Of the 289 individuals who reported the use of such dietary supplements $21 \%$ $(n=61)$ were using creatine supplements, $27 \%$ $(n=78)$ used protein supplements, $13 \%(n=37)$ reported use of fatburner substances (note: fatburners in this category were products that contain, e.g. herbal extracts and/or caffeine. The other more potent fatburner products that contain, e.g. ephedrine, amphetamine or clenbuterol were scored as "stimulants" in the present study in concurrence with the WADA list of banned substances), and 39\% $(n=113)$ used other types of supplements (see Table 4). Of the individuals using these supplements, approximately $30 \%$ were asking about the safety and potential health risks of a certain product, and $30 \%$ of the submitted questions pertained to the status of a specific product in relation to Danish anti-doping regulations.

\section{Discussion}

The main finding of the present study is that the ADD information service is used by male recreational athletes in their mid-20s who are training in gyms. Only a few of the enquirers were associated with competitive sports, and even fewer with elite sports. Fifteen percent of enquirers were users of AAS or other WADA-banned substances and an additional $15 \%$ considered using such substances.

The available age data indicate that individuals who considered the use of doping-listed substances were younger ( $19 \pm 5$ years) than the average user of the enquiry system ( $25 \pm 11$ years), and also younger than those who stated present or previous use of such substances ( $26 \pm 10$ years). These data are comparable to the findings in a previous study on users of the Swedish anti-doping hotline service (Eklöf et al., 2003), and although the age data were limited in the present study, it seems plausible that the present group is representative of the general population of users of the ADD system with respect to individuals who consider use of AAS or other WADA-banned substances.

Table 4. Enquirers who explicitly state the use of WADA-banned substances (upper panel) or dietary supplements (lower panel)

\begin{tabular}{|c|c|c|c|c|c|c|}
\hline & Explicitly state use & Distribution (\%) & Gym & Sport & Male & Female \\
\hline AAS & 129 & 62 & 85 & 7 & 103 & 2 \\
\hline Prohormones & 7 & 3 & 5 & - & 6 & - \\
\hline $\mathrm{HGH}$ & 7 & 3 & 5 & - & 4 & 2 \\
\hline Insulin & 2 & 1 & 1 & - & 2 & - \\
\hline Stimulants & 5 & 3 & 4 & - & 2 & 1 \\
\hline Other* & 58 & 28 & 31 & - & 40 & 6 \\
\hline Total & 208 & $100 \%$ & & & & \\
\hline Creatine/protein supplement & 139 & 48 & 119 & 11 & 130 & 5 \\
\hline "Fat-burner" supplement & 37 & 13 & 22 & 1 & 14 & 12 \\
\hline Other dietary supplement & 113 & 39 & 78 & 11 & 80 & 14 \\
\hline Total & 289 & $100 \%$ & & & & \\
\hline
\end{tabular}

${ }^{*}$ In a certain part of the reports that were based on telephone counselling, the substance drug type was not registered, although it was clear from the record that the enquirer was using a WADA-banned substance, likely AAS.

AAS, anabolic androgenic steroids; HGH, human growth hormone. 
In 2007, approximately 400000 Danes had a gym membership. Approximately $45 \%$ were males and $55 \%$ were females (Kirkegaard, 2007). The lifetime prevalence for use of WADA-banned substances among gym members in 1999 was estimated to be approximately $5 \%(7.8 \%$ for males $)$ based on a survey of 1036 gym members. In $75 \%$ of these cases, AAS was the drug in question (Kulturministeriet, 1999). It follows that the users of the ADD enquiry system are presumably not representative for the general population of gym members in Denmark, and care should therefore be taken when making inferences about gym members or recreational athletes in general based on the current data. Nonetheless, because $15 \%$ of the present enquirers are users of AAS and/or other WADA-banned substances, and an additional $15 \%$ are considering such use, the present results suggest that there is a pronounced interest in and use of doping-listed substances within the exercise training and gym environment. These data are somewhat in agreement with previous work from other countries (Eklöf et al., 2003; Backhouse et al., 2007; Leifman et al., 2008), and taken together, these studies point to a widespread use of PIEDs outside elite sports.

The open attitude of the current population, in which a widespread use of WADA-banned substances is admitted, stands in contrast to how difficult it can be to obtain honest answers from elite athletes in questionnaire-based studies regarding clandestine subjects like doping use (Yesalis et al., 2001). That the present individuals on their own accord report to be using (or to consider using) substances that are not only violating the anti-doping regulations of the national sports federation but are also illegal to possess and distribute according to Danish law illustrates that among recreational strength-training athletes, there is a liberal attitude and less concealment toward such substances compared with what is found within elite sports. While use of WADAbanned substances in elite sport is always hidden or denied, this does not seem to be the case in the current population. This discrepancy may be due to the fact that the ADD counselling is anonymous, and a main source of information for these individuals and further that the sanctions that follow from a potential positive doping test are less severe than those observed by elite athletes.

In Denmark, certain WADA-banned substances are illegal by law "to manufacture, import, export, sell, distribute or possess with the exception of use for the prevention or treatment of diseases or for scientific purposes." The list includes AAS, testosterone, HGH, EPO and drugs with similar effects (Retsinformation, 1999). The objective of the legislation is to prevent the use of AAS and similar substances among recreational and elite athletes.
Possession of small quantities ( $<50$ entities) of these substances results in fines, while selling or distributing any quantity can result in a prison sentence of a minimum of 7 days. Smuggling, trafficking and trade with larger quantities of doping substances lead to police investigations and potentially prison for up to 2 years (Retsinformation, 1999). A unique feature in the Danish anti-doping effort compared with that of other countries is that the ADD, apart from doping testing among elite athletes, since 2005, has also been required by the Danish government to perform doping tests among recreational athletes training in commercial gyms that have signed up to a national anti-doping scheme. According to the regulations, individuals who acquire a positive test are excluded from the gym in which the test was conducted and from all other gyms that are part of the scheme. Furthermore, in line with the rules for athletes in competitive sports, a positive test results in exclusion from participating in any competition governed by the Danish sports confederation for a 2-year period. In the present study period, approximately $20 \%$ of Danish commercial gyms were part of the national anti-doping scheme (covering an estimated $30-40 \%$ of all Danish gym members), but as of November 2008 , approximately $50 \%$ of the gyms were members and about $60 \%$ of gym members were thus associated. From 2005 to 2007 (which includes the period examined in the current study), 565 tests were performed and 127 individuals $(22 \%)$ attained a positive test (ADD, 2007) (Table 5). The testing of recreational athletes in gyms is meant to function as a preventative measure; however, although the present study was carried out at the time of implementation of the testing scheme, the above data and the fact that $>20 \%$ of the tests that are performed in gyms yield a positive doping test underscore that additional efforts are required.

In the present study, it was noted that recreational athletes display an extensive use of dietary supplements such as protein, creatine, so-called "fat burners," herbal extracts, etc. For these PIEDs, which are not banned by WADA, the use is likely facilitated by the aggressive marketing by the industry. This reflects an ambivalent attitude to supplements/drugs that has been observed in modern societies in general (Møldrup \& Morgall, 2001; Møldrup \& Hansen,

Table 5. Number of tests conducted and positive tests in commercial Danish gyms

\begin{tabular}{llll}
\hline Year & $\begin{array}{l}\text { Number of } \\
\text { tests }\end{array}$ & $\begin{array}{l}\text { Number of } \\
\text { positive tests }\end{array}$ & $\begin{array}{l}\text { Percentage of } \\
\text { positives (\%) }\end{array}$ \\
\hline 2005 & 106 & 24 & 23 \\
2006 & 216 & 49 & 23 \\
2007 & 243 & 54 & 22 \\
\hline
\end{tabular}

Source: Anti Doping Denmark, Annual Report, 2007. 


\section{Bojsen-Møller and Christiansen}

2006): on the one hand, there is an open and relaxed attitude to substances that are not banned by WADA, while on the other, users of WADA-banned substances are subject to general societal condemnation at least in association with elite sports. This, however, does not seem to have affected the users of WADAbanned substances in the present study to the same degree as is seen within the elite sports context.

Hardly any of the present users of WADA-banned substances or those considering use, were affiliated with sports, and it therefore seems that the main motivation for use of doping substances in the current population is not increased sports performance but rather enhanced physical appearance or personal image (Kulturministeriet, 1999; Pope et al., 2000; Backhouse et al., 2007). With this in mind, the present data point to an interesting difference with respect to what users of WADA-banned substances are concerned about compared with users of nonbanned substances: while users and those who considered use of WADA-banned substances more often expressed concerns about the health risks associated with their use, users of legal substances did not, to the same degree, express concerns about their health, but were instead interested in gaining information on the risk of obtaining a positive doping test as a result of consuming their specific drug. It thus seems that those who worry the most about doping controls are not individuals using AAS or other WADA-banned substances, but individuals using non-banned substances. Future work is needed to establish whether the increasing effort in Danish gyms with respect to doping controls will have an impact on the attitudes toward use of AAS and other WADA-banned substances in these environments.

Although the actual impact of the ADD information service has not been examined in the present study, the high number of questions submitted per year $(>1200)$ suggests that the service is an often used source of information with respect to dopingrelated issues in Denmark. The typical enquirer of the ADD service is a young male who exercises recreationally in a gym. A considerable number of the examined enquirers $(15 \%)$ were users of AAS and/or other WADA-banned substances, and a similar percentage considered the use of such substances. When combining the present data with previous observations, it seems clear that the pattern of PIED use among the users of the ADD information system does not resemble the general population of gym members in Denmark. Nonetheless, the present body of data underscores previous findings that WADA-banned substances and other PIEDs are widely used outside the elite sports environment.

\section{Perspectives}

In the present study, only a few of the enquirers were associated with competitive sports, and even fewer with elite sports. The results thus emphasize that drug use not only constitutes a problem in relation to fair play within elite sports, but, to a great extent is also a public health issue in the broader population. Although use of PIEDs is abundant in the population, it is nonetheless encouraging that these individuals choose to engage with a public anti-doping institution to seek information on the substances they use or consider using instead of relying solely on internet and locker-room (mis)information. The more than 1000 enquiries per year to the information service illustrates that dialogue with these users is possible and within reach. Future research should seek to evaluate the impact of this dialogue; however, at present, it is important that anti-doping organizations and policy makers continue to facilitate dialogue and not just rely on aggressive anti-doping policies and legislations, which may drive the users "underground" and may limit the ability of both researchers, anti-doping and health services to engage with these individuals.

Key words: anti-doping hotline, WADA-banned substances, anabolic androgenic steroids, recreational exercise.

\section{References}

ADD. Anti Doping Danmark, Årsberetning (annual report), 2007. ADD. Available at http://www. antidoping.dk/da/Raadgivning/Ask_a question.aspx (accessed August 2009).

Backhouse S, McKenna J, Robinson S, Atkin M. International literature review: attitudes, behaviours, knowledge and education - drugs in sport: past, present and future, prepared for World Anti-Doping Agency, 2007.
Bahrke MS, Yesalis CE, Kopstein AN, Stephens JA. Risk factors associated with anabolic-androgenic steroid use among adolescents. Sports Med 2000: 29(6): 397-405.

Cafri G, Thompson JK, Ricciardilli L, McCabe M, Smolak L, Yesalis C. Pursuit of the muscular ideal: physical and psychological consequences and putative risk factors. Clin Psycholog Rev 2005: 25(2): 215-239.
Cohen J, Collins R, Darkes J, Gwartney D. A league of their own: demographics, motivations and patterns of use of 1,955 male adult non-medical anabolic steroid users in the United States. J Int Soc Sports Nutr 2007: 4. Available at http://www.pubmedcentral.nih.gov/ picrender.fcgi?artid $=2131752 \&$ blobtype $=$ pdf

Dawson RT. Drugs in sport - the role of the physician. J Endocrinol 2001: 170: 55-61. 


\section{Use of performance- and image-enhancing substances among recreational athletes}

Donati A. World traffic in doping substances, Report conducted in cooperation with the World Anti Doping Agency, WADA, 2007.

Eklöf AC, Thurelius AM, Garle M, Rane A, Folke S. The anti-doping hot-line, a means to capture the abuse of prohibited substances in the Swedish society and a new service function in clinical pharmacology. Eur J Clin Pharmacol 2003: 59: 571-577.

Evans-Brown M, McVeigh J. Anabolic steroid use in the UK - Briefing paper, 2008.

Evans-Brown M, McVeigh J. Anabolic steroids use in the general population in the United Kingdom. In: Møller V, McNamee M, Dimeo P, eds. Elite sport doping and public health. Odense: University Press of Southern Denmark, 2009: 75-97.

Gray JJ, Ginsberg RL. Muscle dissatisfaction: an overview of psychological and cultural research and theory. In: Thompson JK, Cafri G, eds. The muscular ideal. Psychological, social, and medical perspectives. Washington, DC: American Psychological Association, 2007: 15-39.
Kirkegaard KL. Overblik over den danske fitness-sektor - en undersøgelse af danske fitnesscentre (overview of the Danish fitness sector), Idrættens Analyseinstitut (IDAN), 2007.

Kulturministeriet Doping i Danmark En hvidbog (The Ministry of Culture: White Paper on Doping) Kulturministeriet, 1999.

Leifman H, Rehnman C. Studie om svenska folkets användning av dopningspreparat. Rapport 2008:34. STAD, Stockholm, 2008.

Lenehan P, Bellis M, McVeigh J. Anabolic steroid use in the North West of England. Liverpool: The Drugs and Sport Information Service, 1996.

Loland S, Hanstad DV. What is efficient doping control? A study of procedures and their justification in the planning and carrying out of doping control in sport. Oslo: Norwegian School of Sport Sciences, 2005.

Møldrup C, Hansen RR. Public acceptance of drug use for non-disease conditions. Curr Med Res Opin 2006: 22: 775-780.
Møldrup C, Morgall JM. Risk society reconsidered in a drug context. Health, Risk Soc 2001: 3(1): 59-74.

Monaghan LF. Bodybuilding, drugs and risk. London, UK: Routledge, 2001.

Pope AG, Phillips KA, Olivardia R. The adonis complex. The secret crisis of male obsession. New York: The Free Press, 2000.

Pope HG Jr, Katz DL. Affective and psychotic symptoms associated with anabolic steroid use. Am J Psychiatry 1998: 145(4): 487-490.

Retsinformation, retsinformation.dk, Lov om forbud mod visse dopingmidler, Lov nr. 232 af 21. april 1999 (Law on the ban on certain doping drugs, Law no. 232 of April 21, 1999), 1999.

Yesalis CE, Kopstein AN, Bahrke MS. Difficulties in estimating the prevalence of drug use among athletes. In: Wilson W, Derse E, eds. Doping in elite sport, the politics of drugs in the Olympic movement. Champaign, IL: Human Kinetics, 2001: 43-62. 